\title{
Using Concept Mapping to Improve Parent Implementation of Positive Behavioral Interventions for Children with Challenging Behaviors
}

\author{
Keetam D. F. Alkahtani ${ }^{1}$ \\ ${ }^{1}$ Dept. of Special Education, College of Education, King Saud University, Kingdom of Saudi Arabia \\ Correspondence: Keetam D. F. Alkahtani, Dept. of Special Education, King Saud University, Kingdom of Saudi \\ Arabia. Tel: 966-554-472-227. E-mail: Kalkahtani@ksu.edu.sa
}

Received: August 31, 2013 Accepted: September 27, 2013 Online Published: October 14, 2013

doi:10.5539/ies.v6n11p47

URL: http://dx.doi.org/10.5539/ies.v6n11p47

\begin{abstract}
Children's challenging behaviors can be addressed with effective interventions that can meet children's emotional needs and support their families. Positive Behavioral Interventions and Supports (PBIS) value the family involvement in the process of their child treatment. The intention of this study was to use concept mapping as an adjunct to PBIS in an ecological setting. Participants were a four years old boy diagnosed with ADHD and his mother. A multiple-probe baseline across family routines design was used to evaluate the usefulness of concept mapping as an adjunct to the PBIS process (independent variable) on the level of task-engagement behaviors, challenging behaviors, and parent fidelity of implementation (dependent variables) across three routines. Results recognized concept mapping as a promising practice in parent education.
\end{abstract}

Keywords: Positive Behavioral Interventions and Supports (PBIS), concept mapping, Attention-Deficit Hyperactivity Disorder (ADHD), parent education, mother training, early childhood

\section{Introduction}

Disruptive Behavior Disorders (DBDs) are relatively common in childhood. According to the Diagnostic and Statistical Manual of Mental Disorders-IV-TR (APA, 2006), there are 2-16\% of school children meeting diagnostic criteria for Attention-Deficit Hyperactivity Disorder (ADHD), Oppositional Defiant Disorder (ODD), or Conduct Disorder (CD). Young children with challenging behaviors are at risk for the diagnosis of DBDs. Research has demonstrated that behavior problems that begin in the early years of development is a distinct predictor of later serious behavior disorders as development persists into adolescence and adulthood (Broidy et al., 2003; Campbell, 1995; Kazdin, 1987; Moffitt, 1993; Velderman et al., 2010). Empirical evidence suggests that early intervention is an important component in preventing later negative developmental consequences. Therefore, the development of efficacious interventions which involve parents is essential for long-term benefit on the well-being and quality of life of young children with challenging behaviors and their families (Bor et al., 2002; Dupaul et al., 2002; Kazdin, 1997; Sanders et al, 2003).

There are different approaches to provide parent with interventions to better manage their children's challenging behaviors. Two of the most notable approaches are the expert-driven and the family-driven. The expert-driven approach assumes that behavior specialists conduct comprehensive assessments and develop the interventions, provide the family with the interventions, and also maintain the overall goals of the interventions. Then, to this approach, the parents' involvement is limited to implement the interventions with their child in the home and community settings (Dupaul et al., 2002; Dunst, et al.1999; Gauntlett et al., 2001; Guralnick, 2000; Fox et al., 2002 ). The family-driven approach, which has been used more recently, recognize the importance of the family unique concerns, strengths, and values in every aspect of the child's development, treatment, and progress. As this approach is sensitive to the concerns of families, involves parents in all aspects of a child's treatment. Behavior specialists and parents work cooperatively with each other in an atmosphere of mutual support and respect in order to plan and develop the interventions. Therefore, parents are enabled to participate actively in designing and implementing their child treatment (Dunst, et al.1999; Gauntlett et al., 2001; Fox et al., 2002). Several studies attest that achieving positive treatment outcomes for young children is enhanced when interventions implemented by parents as the primary intervention agents. Interventions should also be embed 
into the natural environment during the daily routines that the family has identified as problematic (Bor et al., 2002; Cripe and Venn, 1997; Hancock et al., 2002; Horner et al., 2000; 2002; Kashinath et al., 2006; Lucyshyn et al., 2007; Pfiffner et al., 2007; Rocha et al., 2007).

Positive behavioral interventions and supports (PBIS) is a comprehensive set of strategies that are based on the principles of applied behavior analysis and evidence-based practices. PBIS can be "applied in the context of early intervention and as children progress through their preschool years into kindergarten and elementary school" (Fox et al., 2002, p.49). One of the PBIS goals is to support the child's family to prevent the display of challenging behavior (Horner, 2000). The philosophy of the PBIS is in line with the family-driven approach. A critical element of PBIS is shaping children' behavior in real-life events through collaboration with the child's family (Fox et al., 2002; Simonsen et al., 2008). Enhancing collaboration and maximizing parental involvement can be achieved and maintained through using coaching strategies that empower parents to be the primary interventionist of their child. Concept mapping is a learning and teaching strategy that could facilitate parental collaboration, involvement, and also ensure generalization of learned skills.

The purpose of the current study is to further the understanding of the PBIS as an early intervention which could be delivered by parents as the primary interventionist for their child during home routines. Specifically, this study focuses on the effect of involving parents in their child's intervention using concept mapping as an adjunct to the PBIS process. Data collection and analysis were guided by the following research question: Will the child's rate of challenging behavior decreases as a result of interventions which are planned and implemented by the parents?

\section{Concept Mapping}

In the early 1970s Joseph Novak and his colleagues presented concept mapping based on Ausubel's assimilation theory (Novak, 1977). Concept mapping is graphical or pictorial tool for brainstorming, organizing, and representing knowledge (Novak, 1998). Learning with concept maps means that the learner is "representing a set of concept meanings embedded in a framework of propositions" (Novak and Gowin, 1984, p. 15). The process of creating a concept map assist learners to structure concepts using their perspective and make meaning of an abstract concept (Novak and Gowan, 1984). Concept mapping could be used for several purposes such as designing a complicated structure, negotiating complex ideas, and solving problems by generating alternative solutions and options (Okebukola, 1992; Plotnic, 1997). With that in mind concept mapping has potential applications in parent education. I assume that concept mapping will support parents' efforts to learn in a meaningful way in an effort toward skills acquisition and optimize long-term application of learned skills.

In parent education, parents are exposed to fundamental concepts and theoretical assumptions behind problem behaviors such as consequences that could maintain problem behaviors. These concepts can be presented in the form of concept map that help to clarify the meaning of each concept and concepts' relationships among each other. Figure 1 shows an example of concept map presents consequences that maintain problem behaviors as stated by O'Neill and his colleagues in 1997. In addition, parents should learn concepts meaningfully by creating concept maps upon their relevant prior knowledge. Meaningful learning is individual and requires association of newly learned concepts with what the learner already knows (Boxtel et al. 2002; Cliburn, 1990; Tergan, 2004). The process of creating a concept map might allow parents to participate actively and to make use of their prior knowledge. Irvine argued that "concept mapping not only facilitates meaningful learning, but makes the learners into active processors of information rather than passive listeners" (1995, p. 1178). Therefore, concept mapping helps parents organize their cognitive frameworks into more powerful and integrated patterns which might lead to consistent, hierarchical, and coherent knowledge structures (Novak, 1998). Concept maps by the behavior specialists can be used to help the parent to understand what is being taught. Likewise, concept maps by the parent help the behavior specialists understand what is being learned.

Another application for concept mapping in parent education, is their use in planning and clarifying daily activities and routines. Concept mapping is a visual organizer that can be integrated with pictures to provide additional clarification. Research indicate that visual support with pictures aid children learning by compensating for limited language abilities (Brown and Pat, 2006; Dettmer et al., 2000; Tobbin and Simpson, 2012). Parents could use concept mapping to visualize daily activities and routines for the child. 


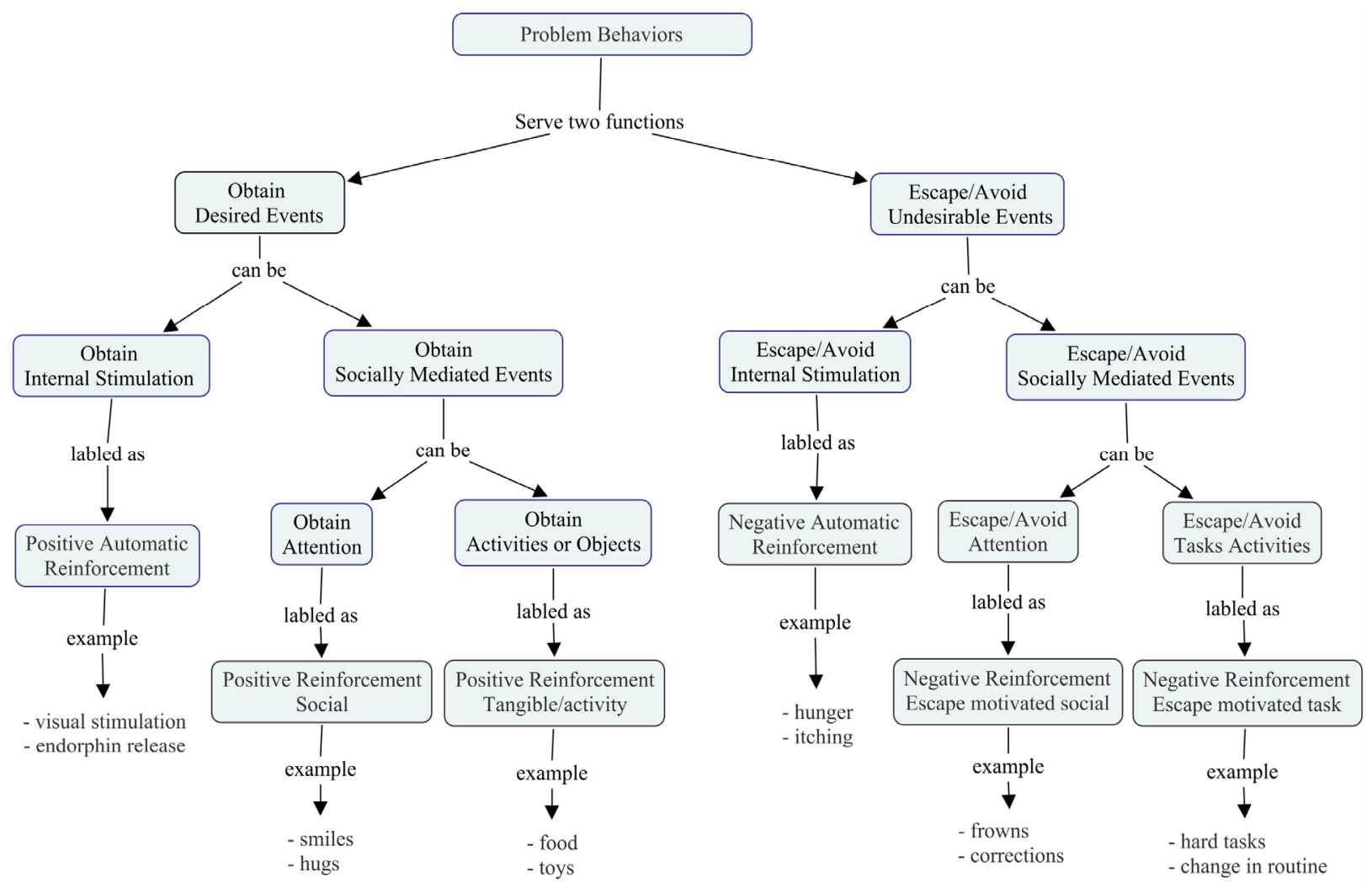

Figure 1. Concept map presents consequences that maintain problem behaviors as stated by O'Neill and his colleagues in 1997

\section{Method}

\subsection{Participants}

The participants in this study were a family that lived in a single-family home in an urban area. The family consists of the father, the mother, and one child. The father ( 35 years old) was a college graduate and a businessman who had to travel often. He travels at least twice a month. The father did not participate in this study, but he believes that his family needs support in dealing with his son's challenging behaviors. Sarah, the mother, is a 32 years old. She is a stay at home mother. She was a college graduate and had previously worked in a bank for three years. Ryan, the son, is a four years and two months old at the start of this study. He had recently been diagnosed with ADHD according to the criteria of the DSM-IV-TR (APA, 2006). Ryan attended a private preschool program five days a week for approximately four hours per day. He enjoyed watching videos at his iPad, playing with his mother, listening to music, and swimming. Ryan, in his earliest infancy, had a feeding difficulties and continuous crying. He also had a history of tantrums. Ryan demonstrated a wide variety of challenging behaviors in both home and kindergarten settings primarily in the form of aggression, destructiveness, and noncompliance. Challenging behaviors are often displayed when Ryan was given requests or time lines to complete an activity and during transitions from one activity to another. At such times, he would often engaged in aggression (e.g., hitting, biting, and throwing objects), physical resistance, run out of a room, crying and screaming. In addition, Ryan had difficulty paying attention and staying on task during pre-academic activities (e.g., match-to-sample task, assembly task, and putting a puzzle together ). Ryan's social skills are underdeveloped. He had difficulty in sharing materials and toys with other children, taking turns and following the rules of play activities. Usually, he played by himself for a few minutes, then he disrupt the play of other children.

Sarah is a member of a support group for parents of children diagnosed with ADHD. I was invited to present a workshop at one of the group's meetings. Sarah, during the workshop, expressed ongoing frustration with the behavior management of her son and requested my advice on how to address his behavior challenges. I asked her to participate in this study and she agreed. I sent the informed consent form to her via email. She signed and returned it, then the study started after receiving the signed consent form. Sarah and her son Ryan were 
considered focus participants. Two research assistants (graduate students) were also involved in this research in the coding of videotapes and providing inter-observer agreement. This study was conducted within the natural context of family routines, and was carried out collaboratively by Sarah and myself. Sarah was highly motivated to address her son's challenging behaviors using a collaborative approach. My role was a facilitator to counsel, advise, guide, and assist Sarah with the process of planning and constructing of a PBIS plan for her son.

\subsection{Design}

The study employed a single case experimental design. A multiple probe design across settings/routines was chosen since it provides an experimental control while data are not collected during every session but rather probes (Barlow et al., 2008). Data were not collected on a continuous basis due to practicality and expense. Multiple probe design is appropriate for evaluating the usefulness of concept mapping as an adjunct to the PBIS process (independent variable) on the level of task-engagement behaviors, challenging behaviors, and parent fidelity of implementation (dependent variables) across three routines. In addition, three weeks following the end of the intervention, weekly maintenance probes for three weeks and five-month follow-up probe were collected.

\subsection{Procedures}

The process of this study is modeled from the general process of the PBIS which include five steps as follows: (a) establishing a family partnership, (b) conducting a functional behavioral assessment (FBA), (c) developing a behavior support plan, (d) implementing an intervention, and (e) monitoring outcomes (Duda et al., 2008; Fox et al., 2002; Lucyshyn et al., 2002). Each of these steps is outlined below.

\subsubsection{Step One: Establishing a Family Partnership}

Understanding the family's structure, strengths, and needs can be achieve by establishing a rapport that based on trust (fox et al., 2002). The initial meeting which held with the entire family was to create a responsive relationship by asking open-ended questions. This meeting was important in developing an open dialog with the father on his feeling and opinion about his role in the intervention. He believed that he will not have the time to participate in this study, but he was pleased that his wife is participating. The following three meetings were with Sarah and her son. Through these meetings, I conducted semi-structured interview to obtain information about the family quality of life, and gained an understanding of the family's relationships, communication, routines and activities. A conceptual framework of the process of PBS and concept mapping was presented in the fifth and sixth meetings.

\subsubsection{Step Two: Conducting a Functional Behavioral Assessment}

This step divided into three sub-steps as follows: (a) training the mother on FBA, (b) identifying behaviors of concern, and (c) conducting a FBA.

\subsubsection{Training the Mother on FBA}

Sarah, the mother, is the primary interventionist. Thus she should be given training in FBA. I trained her in three training sessions, each lasting approximately one hour. Training materials were derived from the work of O'Neill and his colleagues (1997). Training focused on the following content: (a) the concepts and importance of FBA, (b) process of FBA, and (c) types of behavior functions. Training was presented through interactive concept mapping.

\subsubsection{Identifying Behaviors of Concern}

A positive strength-based approach was used throughout the course of identifying and underrating Ryan's challenging behaviors. For example, when Sarah made a statement that highlighted her son deficits (e.g., Ryan does not focus on one thing, he moves from activity to activity), I ask her to replace it with a statement that emphasized Ryan's strengths (e.g., Ryan has a lot of interests, he seems to be interested in two different activities at the same time). Sarah identified a list of Ryan's challenging behaviors. The list was organized according to the frequency with which the behaviors occurred. Ryan's challenging behaviors include aggression, crying and screaming, noncompliance, destructiveness, and impulsivity.

\subsubsection{Conducting a FBA}

Daily videotaped observations were analyzed by Sarah and myself in order to document patterns of Ryan's challenging behaviors. Ryan displays high rates of challenging behaviors during three routines (mealtime, bedtime, and academic time). In these difficult or unclear routines, Ryan's problem behaviors began when he is not sure what he is supposed to do, or does not know how to communicate his needs and feelings. When Ryan misbehave, Sarah will often give up by allowing him to leave the activity. Table 1 displays Ryan's challenging behaviors during routines. 
Table 1. Ryan's challenging behaviors during routines

\begin{tabular}{|c|c|c|c|}
\hline Routine & Description & $\begin{array}{l}\text { Challenging } \\
\text { Behaviors }\end{array}$ & Function \\
\hline \multirow[t]{2}{*}{ Mealtime } & $\begin{array}{l}\text { Sarah placed food at the table. Bring or ask Ryan to come } \\
\text { to the eating area. She set in front of Ryan and ask him to } \\
\text { eat. He set in for one minute before engaging in } \\
\text { challenging behaviors. Sarah chose to intervene on this } \\
\text { routine first because her son eating problems - not eating }\end{array}$ & $\begin{array}{l}\text { Refusing to eat. } \\
\text { Throwing food. } \\
\text { Resist sitting at the } \\
\text { table. }\end{array}$ & Escape. \\
\hline & $\begin{array}{l}\text { enough. He drink water, milk, and juice out of his sippy } \\
\text { cups. He mainly eat baby food, and does not eat solid } \\
\text { food except cookies, cakes, crackers, and sweets. } \\
\text { Duration of this routine is between } 5 \text { to } 8 \text { minutes. }\end{array}$ & $\begin{array}{l}\text { kicking his chair, } \\
\text { crying and screaming. }\end{array}$ & $\begin{array}{l}\text { Communicate } \\
\text { or Recruit } \\
\text { attention. }\end{array}$ \\
\hline \multirow[t]{2}{*}{ Bedtime } & $\begin{array}{l}\text { Sarah carry Ryan to his bedroom. She put him into his } \\
\text { pajamas, put him to bed, and read to him a story. As she } \\
\text { left his bedroom, he engage in challenging behaviors. } \\
\text { She, to stop him, play with him or lie on the bed next to } \\
\text { him until he fell asleep. }\end{array}$ & $\begin{array}{l}\text { Coming out of his } \\
\text { room. } \\
\text { Throwing his blanket. } \\
\text { Crying and } \\
\text { screaming. }\end{array}$ & $\begin{array}{l}\text { Communicate } \\
\text { or Recruit } \\
\text { attention. }\end{array}$ \\
\hline & Duration of this routine is between 82 to 97 minutes. & $\begin{array}{l}\text { Getting out of bed } \\
\text { and play with toys or } \\
\text { watches videos at his } \\
\text { iPad. }\end{array}$ & Tangible. \\
\hline \multirow[t]{2}{*}{$\begin{array}{l}\text { Academic } \\
\text { time }\end{array}$} & $\begin{array}{l}\text { Sarah set Ryan on his chair and sat in front of him. She } \\
\text { place learning materials on the desk and ask her son to } \\
\text { work with her. Ryan respond a few minutes, then he } \\
\text { display challenging behaviors. Sarah give up and allow } \\
\text { him to leave to another activity. } \\
\text { Duration of this routine is between } 8 \text { to } 23 \text { minutes. }\end{array}$ & $\begin{array}{l}\text { Getting out of his } \\
\text { chair. } \\
\text { Noncompliance } \\
\text { "saying no, or not } \\
\text { responding to an } \\
\text { instruction or prompt } \\
\text { within } 5 \text { seconds" } \\
\text { Throwing his learning } \\
\text { materials. }\end{array}$ & Escape. \\
\hline & & $\begin{array}{l}\text { Crying and } \\
\text { screaming. } \\
\text { Hitting his mother } \\
\text { with his hands. }\end{array}$ & $\begin{array}{l}\text { Communicate } \\
\text { or Recruit } \\
\text { attention. }\end{array}$ \\
\hline
\end{tabular}

\subsubsection{Step Three: Developing a Behavior Support Plan}

Sarah and myself, based on the FBA, developed a hypothesis that problem behaviors occur to (a) avoid demands of routines that Ryan finds difficult, (b) communicate his needs and feelings, and (c) recruit attention and interact with those around him. Then, we developed behavior support plan to address the behavioral hypothesis. The plan was developed using concept mapping strategy which offers the opportunity for us to engage in a mutual problem-solving process that lead to more meaningful interventions. The main goal of the plan was to help Ryan communicate and understand instructions better. This was addressed mainly through teaching him feeling words to talk about how he is feeling, and the use of concept maps with pictures to illustrate each step of the activity.

\subsubsection{Step Four: Implementing an Intervention}

Implementation performed in three different stages: baseline, intervention, and generalization.

\subsubsection{Baseline}

First, by analyzing previous videotapes that had been made during the pre-baseline meetings, I and two research assistants defined and coded Ryan's challenging and task-engagement behaviors in each routine. Challenging behavior was defined as any act that impede the successful completion of the routine (e.g., crying, screaming, and throwing objects). Task-engagement behavior was also defined as any act that demonstrate involvement in the successful completion of the routine (e.g., gazing at the mother face or body, following his mother instructions, and showing interest in the activity). Then, I asked Sarah to carry out usual daily routines without any change in her behavior. During the baseline period every session was videotaped. Data were analyzed daily and graphed visually. Finally, this stage ended when a stable behavioral baseline was established for each routine. 
Baselines were established over three days, and all routines had three baseline sessions.

\subsubsection{Intervention}

An action plan was decided ahead to implementation. In this action plan, Sarah and myself used videotaped sessions, that were randomly selected from the baseline stage, to develop and tailor interventions. We also prepared materials, and developed a fidelity check-list for implementation of the PBIS plan. Intervention was applied in two target routines (mealtime, and bedtime). The first session for each routine was treated as a training session to guide Sarah and assist her, as needed, on implementing the interventions. Sarah, during all other sessions, was the primary interventionist for her son. The multi-component PBIS plan include interventions to prevent challenging behavior, and to increase engagement during the routines. Daily discussions were held to review how the routine went, and fidelity of implementation of the interventions. This stage took up five weeks, and ended when substantial improvement has been occurred in each routine.

\subsubsection{Generalization}

Academic time was selected as generalization routine. During this routine I asked Sarah to develop and implement interventions without consulting me. Significant improvement was achieved in three weeks.

\subsubsection{Step Five: Monitoring Outcomes}

Evaluation of outcomes was conducted through two follow-up stages; three weeks after intervention completion, and again five months later. The follow-up consisted of interview with the family, and five consecutive days of videotaping Ryan's behavior during routines (mealtime, bedtime, and academic time).

\section{Data Collection and Reliability}

Pre- and post-interview recorded on audiotape and then transcribed. All sessions were videotaped using a small wireless camera "nanny camera". The session's length varied from 5 to $97 \mathrm{~min}$, and was dependent upon the amount of time required for completing each routine. All data were entered into Microsoft Excel and visual analysis were completed following a session and prior to the next session.

\subsection{Inter-Observer Agreement}

Two observers (research assistants) reached minimum of $88 \%$ agreement on videotaped pre-baseline sessions. All sessions were evaluated and scored daily using a 15 -second continuous interval system. Inter-observer agreement was determined for each session at all the stages (baseline, intervention, and follow-up). The percentage of agreement was calculated by dividing the total number of agreements by the total number of agreements and disagreements with the result multiplied by 100 (Kennedy, 2004; Tawney and Gast, 1984). The overall inter-observer agreement ranged from $88 \%$ to $98 \%$. The results of inter-observer agreement are shown in Table 2.

Table 2. Inter-observer agreement

\begin{tabular}{|c|c|c|c|c|}
\hline Routine & & $\begin{array}{l}\text { Mean Pe } \\
\text { (Range) }\end{array}$ & eement & \\
\hline \multirow{3}{*}{ Mealtime } & Challenging behavior & $\begin{array}{l}\text { Baseline } \\
92 \\
(92-95)\end{array}$ & $\begin{array}{l}\text { Intervention } \\
93 \\
(91-98)\end{array}$ & $\begin{array}{l}\text { Follow-up } \\
93 \\
(90-97)\end{array}$ \\
\hline & Task-engagement behavior & 91 & 92 & 91 \\
\hline & Fidelity of Implementation & $\begin{array}{l}93 \\
(91-94)\end{array}$ & $\begin{array}{l}94 \\
(92-97)\end{array}$ & $\begin{array}{l}95 \\
(93-97)\end{array}$ \\
\hline \multirow[t]{2}{*}{ Bedtime } & Challenging behavior & $\begin{array}{l}93 \\
(90-94)\end{array}$ & $\begin{array}{l}94 \\
(92-97)\end{array}$ & $\begin{array}{l}93 \\
(91-96)\end{array}$ \\
\hline & Task-engagement behavior & $\begin{array}{l}92 \\
(88-96)\end{array}$ & $\begin{array}{l}91 \\
(89-98)\end{array}$ & $\begin{array}{l}92 \\
(90-95)\end{array}$ \\
\hline \multirow{4}{*}{ Academic time } & Fidelity of Implementation & $\begin{array}{l}95 \\
(92-96)\end{array}$ & $\begin{array}{l}93 \\
(90-94)\end{array}$ & $\begin{array}{l}93 \\
(89-97)\end{array}$ \\
\hline & Challenging behavior & $\begin{array}{l}93 \\
(90-97)\end{array}$ & $\begin{array}{l}94 \\
(90-98)\end{array}$ & $\begin{array}{l}94 \\
(91-95)\end{array}$ \\
\hline & Task-engagement behavior & $\begin{array}{l}93 \\
(88-98)\end{array}$ & $\begin{array}{l}94 \\
(91-97)\end{array}$ & $\begin{array}{l}94 \\
(90-95)\end{array}$ \\
\hline & Fidelity of Implementation & $\begin{array}{l}96 \\
(90-97)\end{array}$ & $\begin{array}{l}96 \\
(92-98)\end{array}$ & $\begin{array}{l}95 \\
(90-96)\end{array}$ \\
\hline
\end{tabular}




\subsection{Intervention Fidelity}

A checklist that highlighted the interventions to be implemented in each routine was developed to document the degree of accuracy with which the interventions are implemented. Two observers (research assistants), while observing the videotape, wrote a plus sign $(+)$ in the space next to interventions implemented correctly and a minus sign (-) in the space next to interventions implemented incorrectly. Procedural integrity was calculated for each session through all stages (baseline, intervention, and follow-up) by dividing the number of interventions implemented by the total number of interventions on the checklist multiplied by $100 \%$ (Kennedy, 2004; Tawney and Gast, 1984).

\subsection{Social Validity}

In order to assess social validity of using PBIS and concept mapping technique, following each intervention stage for each routine, the mother was asked a six-item questionnaire with Likert-type responses in which $1=$ strongly disagree, $3=$ natural, and $5=$ strongly agree. The results of social validity are shown in Table 3 .

Table 3. Social validity questionnaire

\begin{tabular}{|c|c|c|c|c|}
\hline Statement & Mealtime & Bedtime & $\begin{array}{l}\text { Academic } \\
\text { time }\end{array}$ & Follow-up \\
\hline PBIS aid my child to develop his full potential. & 5 & 5 & 5 & 5 \\
\hline $\begin{array}{l}\text { Concept mapping aid my child to understand routine } \\
\text { activities. }\end{array}$ & 5 & 5 & 5 & 5 \\
\hline Creating a concept map is time-consuming. & 1 & 1 & 1 & 1 \\
\hline It is difficult to implement concept mapping. & 1 & 1 & 1 & 1 \\
\hline $\begin{array}{l}\text { The process of creating a concept map is a vital } \\
\text { element in understanding my child behavior. }\end{array}$ & 5 & 5 & 5 & 5 \\
\hline $\begin{array}{l}\text { PBIS and concept mapping greatly assisted me in } \\
\text { managing my child behavior. }\end{array}$ & 5 & 5 & 5 & 5 \\
\hline
\end{tabular}

Note: 1 = strongly disagree; $3=$ natural 5 = strongly agree.

\section{Results}

The results are shown in Tables 4 and 5. Visual analysis presented in Figure 2 show the following: (a) Ryan's percentage of intervals in which the challenging behaviors were observed, (b) Ryan's percentage of intervals in which task-engagement behaviors took place, and (c) Sarah's percentage of fidelity of implementation across all sessions, phases, and routines. Percentage of intervals in which the behaviors (challenging, task-engagement, and fidelity of implementation ) occurred is plotted on the ordinate and the observation sessions are plotted on the abscissa. Baselines data for challenging behavior in each routine were stable and displayed high level of challenging behaviors. Challenging behavior occurred during a mean of $89 \%$ (range $=85 \%-92 \%$ ) of intervals across all routines. During the intervention for each of the routine, Ryan's challenging behavior decreased to a mean of $53 \%$ (range $=20 \%-85 \%$ ) of intervals, and the follow-up data were consistent with those of the intervention phase. For task-engagement behaviors, the baseline data were stable and occurred at a low level, with a mean of $11 \%$ (range $=8 \%-15 \%)$ of intervals across all routines . Ryan's engagement behavior rose to a mean of $47 \%$ (range $=15 \%-52 \%$ ) of intervals during the intervention and follow-up phases. The fidelity of implementation data at the baseline show that implementation occurred at a low level during a mean of $6 \%$ (range $=4 \%-9 \%$ ) of intervals across all routines. Implementation, during the intervention and follow-up phases, increased to a mean of $96 \%$ (range $=90 \%-98 \%$ ).

Effect size calculated for each routine using percentage of non-overlapping data points (PND) by dividing the number of non-overlapping points by the total number of intervention points and multiplying by 100 (Scruggs et al., 1986). All PNDs between baseline and treatment phases were higher than $90 \%$ which indicate highly effective treatment.

The post-interview data point toward positive changes and an improvement in overall family quality of life. Sarah pointed out that her family was able to have more quality time. She also was less stress and worry about her son engaging in challenging behavior during daily routines or on community outings. 
Table 4. Ryan's behavior percentages averages

\begin{tabular}{lllll}
\hline Routine & & \multicolumn{2}{l}{$\begin{array}{l}\text { Mean Percentages of Behavior } \\
\text { (Range) }\end{array}$} & \\
& Challenging behavior & 89 & Intervention & Follow-up \\
Mealtime & & 53 & 29 \\
& Task-engagement & 11 & $(30-75)$ & $(28-30)$ \\
& behavior & $(9-13)$ & 47 & 71 \\
& Challenging behavior & 87 & $47-70)$ & $(70-72)$ \\
Bedtime & & $(85-90)$ & $(20-76)$ & 20 \\
& Task-engagement & 13 & 52 & $(18-23)$ \\
& behavior & $(10-15)$ & $(24-80)$ & 79 \\
Academic time & Challenging behavior & 90 & 58 & $(77-80)$ \\
& & $(88-92)$ & $(30-85)$ & 29 \\
& Task-engagement & 10 & 43 & $(27-30)$ \\
& behavior & $(8-12)$ & $(15-70)$ & 71 \\
& & & & $(70-73)$ \\
\hline
\end{tabular}

Table 5. Sara's fidelity of implementation averages

\begin{tabular}{llll}
\hline Routine & $\begin{array}{l}\text { Mean Percentages of Fidelity } \\
\text { (Range) }\end{array}$ & \\
\hline \multirow{3}{*}{ Mealtime } & Baseline & Intervention & Follow-up \\
& 5 & 96 & 97 \\
Bedtime & $(4-7)$ & $(90-98)$ & $(96-98)$ \\
& 7 & 97 & 97 \\
Academic & $(5-9)$ & $(96-98)$ & $(96-98)$ \\
time & $(5-9)$ & 97 & 98 \\
\hline
\end{tabular}

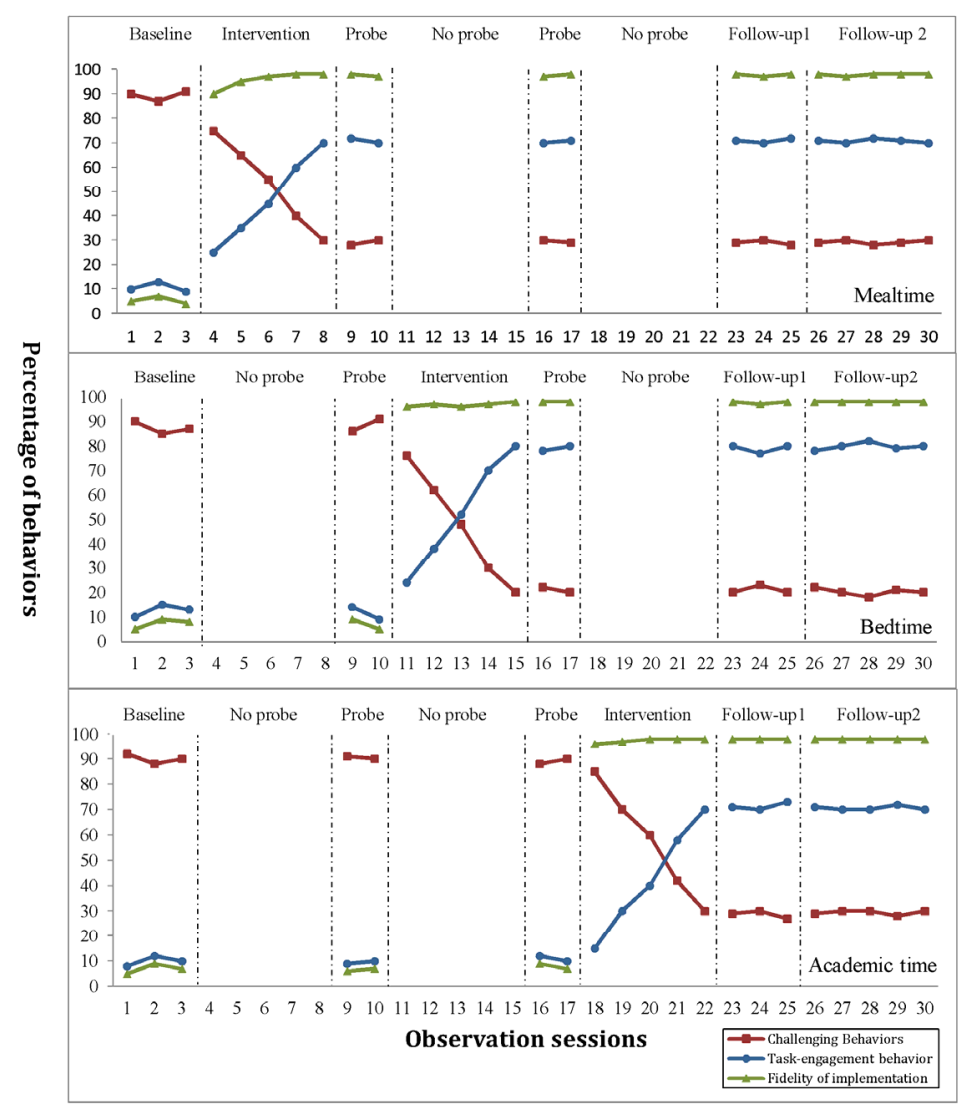

Figure 2. Percentage of intervals in which the behaviors were observed 


\section{Discussion}

The overall result indicates that there is a sharp reduction in the levels of challenging behaviors and elevation in the levels of engagement behaviors in each of the three routines when intervention was introduced and throughout the follow-up phases. The result also point to a correlation between the level of fidelity of implementation of the strategies used by Sarah and the level of Ryan's challenging behavior; when the level of implementation is higher the level challenging behavior is lower. These results support the conclusion that parents should be in the lead in the intervention process. Empowering parent results in high social validity and ensure contextual fit and maintenance of the interventions (Clarke et al., 1999; Conroy et al., 2005; Horner, 2000).

The findings of this study suggest that using concept mapping as an adjunct to the PBIS process could assist and motivate parents to involve intimately in planning and implementing of an effective interventions. Concept mapping create a positive functional relationship and additional mode of communication which can help the child, parents, and the interventionist to have a better understanding of their environment and expectations. However, limitations pertaining to the design, participants, and the nature of this exploratory study necessitate that the result be interpreted with caution. Further research should be conducted to implement concept mapping in parent education.

\section{Acknowledgements}

I gratefully acknowledge that this research project was supported by a grant from the Research Center for the Humanities, Deanship of Scientific Research, King Saud University.

\section{References}

American Psychiatric Association. (2006). Diagnostic and statistical manual of mental disorders (4th ed.), text revision). Washington, DC: Author.

Barlow, D., Nock, M., \& Hersen, M. (2008). Single case experimental designs: Strategies for studying behavior change (3rd ed.). New York: Pergamon Press.

Bor, W., Sanders, M., \& Markie-Dadds, C. (2002). The effects of the triple p - positive parenting program on preschool children with co-occurring disruptive behavior and attentional/hyperactive difficulties. Journal of Abnormal Child Psychology, 30(6), 571-587. http://dx.doi.org/10.1023/A:1020807613155

Boxtel, C., Linden, J., Roelofs, E., \& Erkens, G. (2002). Collaborative concept mapping: Provoking and supporting meaningful discourse. Theory into practice, 41(1), 40-46. http://dx.doi.org/10.1207/s15430421tip4101_7

Broidy, L., Nagin, D., Tremblay, R., Bates, J., Brame, B., \& Dodge, K. (2003). Developmental trajectories of childhood disruptive behaviors and adolescent delinquency: A six-site, cross-national study. Developmental Psychology, 39, 222-245. http://dx.doi.org/10.1037/0012-1649.39.2.222

Brown, K., \& Pat, M. (2006). Contingency Mapping: Use of a Novel Visual Support Strategy as an Adjunct to Functional Equivalence Training. Journal of Positive Behavior Interventions, 8, 155-164. http://dx.doi.org/10.1177/10983007060080030401

Campbell, S. (1995). Behavior problems in preschool children: A review of recent research. Journal of Child Psychology and Psychiatry, 36, 113-149. http://dx.doi.org/10.1111/j.1469-7610.1995.tb01657.x

Clarke, S., Dunlap, G., \& Vaughn, B. (1999). Family-centered, assessment-based intervention to improve behavior during an early morning routine. Journal of Positive Behavior Interventions, 1, 235-241. http://dx.doi.org/10.1177/109830079900100406

Cliburn, J. (1990). Concept maps to promote meaningful learning. Journal of College Science Teaching, 19(4), 212-217.

Conroy, M., Dunlap, G., Clarke, S., \& Alter, P. (2005). A descriptive analysis of positive behavioral intervention research with young children with challenging behavior. Topics in Early Childhood Special Education, 25, 157-166. http://dx.doi.org/10.1177/02711214050250030301

Cripe, J., \& Venn, M. (1997). Family-guided routines for early intervention services. Young Exceptional Children, 1, 18-26. http://dx.doi.org/10.1177/109625069700100104

Dettmer, S., Simpson, R., Myles, B., \& Ganz, J. (2000). The use of visual supports to facilitate transitions of students with autism. Focus on Autism and Other Developmental Disabilities, 15, 163-169. http://dx.doi.org/10.1177/108835760001500307 
Duda, M., Clarke, S., Fox, L., \& Dunlap, G. (2008). Implementation of Positive Behavior Support with a Sibling Set in a Home Environment. Journal of Early Intervention, 30, 213-36. http://dx.doi.org/10.1177/1053815108319124

Dunst, C., Trivette, C., \& Deal, A. (1999). Enabling and empowering families: Principles and guidelines for practice. Brookline Books.

Dupaul, J., Eckert, L., \& Mcgoey, E. (2002). Early intervention for preschool-age children with ADHD: A literature review. Journal of Emotional and Behavioral Disorders, 10(1), 14-28. http://dx.doi.org/10.1177/106342660201000103

Fox, L., Dunlap, G., \& Cushing, L. (2002). Early intervention, positive behavior support, and transition to school. Journal of Emotional and Behavioral Disorders, 10(3), 149-157. http://dx.doi.org/10.1177/10634266020100030301

Gauntlett, E., Hugman, R., Kenyon, P., \& Logan P. (2001). A meta-analysis of the impact of community-based prevention and early intervention. Canberra, Australia: Commonwealth Department of Family and Community Services. $\quad$ Retrieved April 21, 2012, from http://www.homemods.info/resource/bibliography/metaanalysis_impact_communitybased_prevention_and_ early_intervention_action

Guralnick, M. (2000). Early childhood intervention: Evolution of a system. Focus on Autism and Other Developmental Disabilities, 15(2), 68-83. http://dx.doi.org/10.1177/108835760001500202

Hancock, T., Kaiser, A., \& Delaney, E. (2002). Teaching parents of preschoolers at high risk: Strategies to support language and positive behavior. Topics in Early Childhood Special Education, 22, 191-212. http://dx.doi.org/10.1177/027112140202200402

Horner, R. (2000). Positive Behavior Supports. Focus on Autism and Other Developmental Disabilities, 15(2), 97-105. http://dx.doi.org/10.1177/108835760001500205

Horner, R., Carr, E., Strain, P., Todd, A., \& Reed, H. (2002). Problem behavior interventions for young children with autism: A research synthesis. Journal of Autism and Developmental Disorders, 32, 423-446. http://dx.doi.org/10.1023/A:1020593922901

Irvine, L. (1995). Can concept mapping be used to promote meaningful learning in nurse education? Journal of Advanced Nursing, 21(6), 1175-1179. http://dx.doi.org/10.1046/j.1365-2648.1995.21061175.x

Kashinath, S., Woods, J., \& Goldstein, H. (2006). Enhancing generalized teaching strategy use in daily routines by parents of children with autism. Journal of Speech, Language, and Hearing Research, 49, 466-485. http://dx.doi.org/10.1044/1092-4388

Kazdin, A. (1987). Treatment of antisocial behavior in children: Current status and future directions. Psychological Bulletin, 102, 187-203. http://dx.doi.org/10.1037/0033-2909.102.2.187.

Kazdin, A. (1997). Parent management training: Evidence, outcomes and issues. Journal of the American Academy of Child and Adolescent Psychiatry, 36, 1349-1356. http://dx.doi.org/10.1097/00004583-199710000-00016

Kennedy, C. (2004). Single-case designs for educational research. Boston: Pearson Education.

Lucyshyn, J., Albin, R., Horner, R., Mann, J., Mann, J., \& Wadsworth, G. (2007). Family implementation of positive behavior support for a child with autism: Longitudinal, single-case, experimental, and descriptive replication and extension. Journal of Positive Behavior Interventions, 9, 131-150. http://dx.doi.org/10.1177/10983007070090030201

Lucyshyn, J., Horner, R., Dunlap, G., Albin, R., \& Ben, K. (2002). Positive behavior support with families. In J. M. Lucyshyn, G. Dunlap, \& R. W. Albin (Eds.), Families and positive behavior support: Addressing problem behavior in family contexts (pp. 3-43). Baltimore: Brookes.

Moffitt, T. E. (1993). Adolescent-limited and life-course-persistent antisocial behavior: A developmental taxonomy, Psychological Review, 100, 674-701. Retrieved April 17, 2012, from http://www.psychology.sunysb.edu/ewaters/552-04/slide\%20sets/brian_mcfarland_aggression/moffitt_ aggression.pdf

Novak, J. (1977). A theory of education. Ithaca, New York: Cornell University Press.

Novak, J. (1998). Learning, Creating, and Using Knowledge. New Jersey: Lawrence Erlbaum Association. 
Novak, J., \& Gowin, D. (1984). Learning how to learn. Cambridge University Press.

Okebukola, P. (1992). Can good concept mappers be good problem solvers in science? Research in Science and Technological Education, 10(2), 153-169. http://dx.doi.org/10.1080/0263514920100204

O'Neill, R. E., Horner, R. H., Albin, R. W., Sprague, J. R., Storey, K., \& Newton, J. S. (1997). Functional assessment and program development for problem behavior: A practical handbook (2nd ed.). Pacific Grove, CA: Brooks/Cole.

Pfiffner, L., Mikami, A., Huang-Pollock, C., Easterlin, B., Zalecki, A., \& McBurnett, K. (2007). A randomized controlled trial of integrated home-school behavioral treatment for ADHD, predominantly inattentive type. Journal of the American Academy of Child and Adolescent Psychiatry, 46, 1041-1050. http://dx.doi.org/10.1097/chi.0b013e318064675f

Plotnic, E. (1997). Concept mapping: A graphical system for understanding the relationship between concepts. ERIC Clearinghouse on Information and Technology, Syracuse University, 4-194 Center for Science and Technology, Syracuse, NY. ERIC Document Reproduction Service No. ED 407938. Retrieved June 23, 2012, from http://www.ericdigests.org/1998-1/concept.htm

Rocha, M., Schreibman, L., \& Stahmer, A. (2007). Effectiveness of training parents to teach joint attention in children with autism. Journal of Early Intervention, 29, 154-172. http://dx.doi.org/10.1177/105381510702900207

Sanders, M., Markie-Dadds, C., \& Turner, K. (2003). Theoretical, scientific and clinical foundations of the Triple P Positive Parenting Program: A population approach to the promotion of parenting competence. Parenting Research and Practice Monograph, 1, 1-24. Retrieved June 27, 2011, from http://www.triplep.be/sites/triplep/files/Parenting_Research_and_Practice_Monograph_No.1_0_1.pdf

Scruggs, E., Mastropieri, A., Cook, B., \& Escobar, C. (1986). Early intervention for children with conduct disorders: A quantitative synthesis of single-subject research. Behavioral Disorders, 11, 260-271.

Simonsen, B., Sugai, G., \& Negron, M. (2008). School wide positive behavior supports: Primary systems and practices. Teaching Exceptional Children, 40, 32-40.

Tawney, J., \& Gast, D. (1984). Single subject research in special education. Columbus, OH: Merrill Publishing Company.

Tergan, S. (2004). Concept maps for managing individual knowledge. Paper presented at the first international conference on concept mapping: Pamplona, Spain. Retrieved April 27, 2012, from http://www.iwm-kmrc.de/workshops/sim2004/pdf_files/Tergan.pdf

Tobbin, C., \& Simpson, R. (2012). Consequence maps: A novel behavior management tool for educators. Teaching Exceptional Children, 44, 68-75.

Velderman M., Crone R., Wiefferink H., \& Reijneveld A. (2010). Identification and management of psychosocial problems among toddlers by preventive child health care professionals. The European Journal of Public Health, 20(3), 332-338. http://dx.doi.org/10.1093/eurpub/ckp169

\section{Copyrights}

Copyright for this article is retained by the author(s), with first publication rights granted to the journal.

This is an open-access article distributed under the terms and conditions of the Creative Commons Attribution license (http://creativecommons.org/licenses/by/3.0/). 